\title{
Blockchain Personal Health Records: Systematic Review
}

Hao Sen Andrew Fang ${ }^{1}$, MBBS, MMed, MTech; Teng Hwee Tan², MBBS, FRANZCR; Yan Fang Cheryl Tan ${ }^{3}$, MBBS, MMed, FCFP; Chun Jin Marcus Tan², MBBS, MMed, FRCOphth, MTech

\footnotetext{
${ }^{1}$ SingHealth Polyclinics, Singapore, Singapore

${ }^{2}$ National University Health System, Singapore, Singapore

${ }^{3}$ SingHealth Community Hospitals, Singapore, Singapore
}

\section{Corresponding Author:}

Hao Sen Andrew Fang, MBBS, MMed, MTech

SingHealth Polyclinics

167, Jalan Bukit Merah

Connection One, Tower 5, \#15-10

Singapore, 150167

Singapore

Phone: 6593690001

Email: andrew.fang.h.s@singhealth.com.sg

\section{Abstract}

Background: Blockchain technology has the potential to enable more secure, transparent, and equitable data management. In the health care domain, it has been applied most frequently to electronic health records. In addition to securely managing data, blockchain has significant advantages in distributing data access, control, and ownership to end users. Due to this attribute, among others, the use of blockchain to power personal health records (PHRs) is especially appealing.

Objective: This review aims to examine the current landscape, design choices, limitations, and future directions of blockchain-based PHRs.

Methods: Adopting the PRISMA (Preferred Reporting Items for Systematic Reviews and Meta-analyses) guidelines, a cross-disciplinary systematic review was performed in July 2020 on all eligible articles, including gray literature, from the following 8 databases: ACM, IEEE Xplore, MEDLINE, ScienceDirect, Scopus, SpringerLink, Web of Science, and Google Scholar. Three reviewers independently performed a full-text review and data abstraction using a standardized data collection form.

Results: A total of 58 articles met the inclusion criteria. In the review, we found that the blockchain PHR space has matured over the past 5 years, from purely conceptual ideas initially to an increasing trend of publications describing prototypes and even implementations. Although the eventual application of blockchain in PHRs is intended for the health care industry, the majority of the articles were found in engineering or computer science publications. Among the blockchain PHRs described, permissioned blockchains and off-chain storage were the most common design choices. Although 18 articles described a tethered blockchain PHR, all of them were at the conceptual stage.

Conclusions: This review revealed that although research interest in blockchain PHRs is increasing and that the space is maturing, this technology is still largely in the conceptual stage. Being the first systematic review on blockchain PHRs, this review should serve as a basis for future reviews to track the development of the space.

(J Med Internet Res 2021;23(4):e25094) doi: 10.2196/25094

\section{KEYWORDS}

blockchain; personal health records; electronic health records; distributed ledger; systematic review

\section{Introduction}

\section{Background}

Personal health records (PHRs) are a form of electronic health records (EHRs). PHRs are unique in that patients themselves can access, manage, and share their health information [1]. The benefits of PHRs include patient empowerment, which leads to improved outcomes and reduced health care costs $[2,3]$. Although interest in PHRs has been increasing, their adoption remains low [4,5]. One of the oft-cited reasons is related to privacy and security concerns owing to an increasing trend of 
health information breaches [6,7]. Another reason is the lack of perceived usefulness to patients [7].

Blockchain technology was introduced through Bitcoin in 2008 [8]. It is considered a general-purpose technology and has since been successfully applied across several different industries $[9,10]$. In the health care industry, EHRs were found to be the most commonly used case for blockchain applications [11-14]. Compared with conventional data management methods that rely on on-premise data servers or third-party cloud services, blockchain's distributed ledger technology offers a novel alternative. This could potentially address the privacy and security concerns surrounding EHRs [15]. Specifically for application to PHRs, blockchain also has the ability to decentralize control and incorporate incentive mechanisms through smart contracts, which can further entice its general use and increase adoption [16]. These advantages, among others, have motivated efforts to test the feasibility and implement blockchain PHRs [17-19].

The research space in which EHRs and blockchain intersect is still in its infancy, with the first blockchain EHR introduced in 2016 [20]. Systematic reviews covering this space so far have considered EHRs as a collective entity. Mayer et al [21] provided an overview of the ecosystem of blockchain EHRs while also proposing a taxonomy for the space. Shuaib et al [22] looked at the main areas of focus when implementing a blockchain EHR and the remaining issues to be addressed, whereas Vazirani et al [23] assessed the feasibility of blockchain as a method of managing health care records efficiently.

Given that one of the inherent properties of blockchain is its decentralized nature, in which data ownership is placed in the hands of individual users, some have proposed that blockchain may be more suitably applied to PHRs specifically rather than EHRs in general [19,24-26]. In this paper, we aim to systematically review the following: (1) the current landscape and trends of blockchain-based PHRs (blockchain PHRs), (2) the attributes of various blockchain PHRs that have been described, and (3) the current limitations and future directions for blockchain PHRs. To the best of our knowledge, this is the first systematic review examining blockchain with PHRs. We hope that this review will serve as a useful reference, especially for those intending to develop a blockchain PHR and for future reviews in this area.

To provide more context for subsequent sections of this paper, we will first explain pertinent blockchain concepts and take the opportunity to introduce some terminology specific to blockchain. This is by no means an exhaustive explanation of blockchain.

\section{What Is a Blockchain?}

A blockchain can be thought of as a shared (or distributed) database that is spread across multiple sites and participants. For new data to be added to a blockchain, they are first compiled into a block, which is simply a collection of records to be added to the database. The block is then combined with some data (a hash key) from the previous block through a cryptographic technique called hashing before it is added. As it combines the previous block's hash key, each new block is tied to all its predecessors in the form of a chain-hence the term blockchain (Figure 1).

Figure 1. Illustration of how blocks of data are linked together in a blockchain through hashing. To add a new record (eg, Record \#7) to the blockchain, this is first grouped with other records (Records \#6, \#8, and \#9). The group of records is then combined with a hash key from the previous block (hash key 2) and then put through a hashing algorithm to produce a new hash key (hash key 3). The new records, along with hash keys 2 and 3, are now part of a new block (Block $\mathrm{N}+3$ ) that has been added to the blockchain. This process continues as new records are added.

\section{Block N+1}

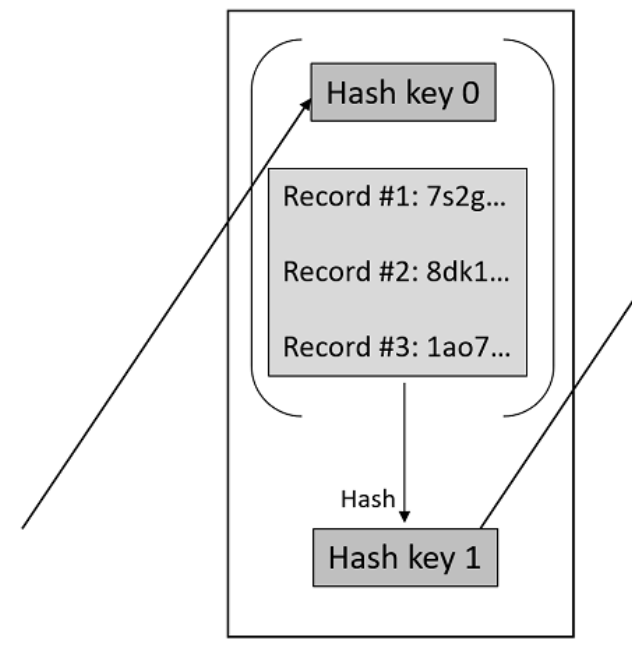

Block N+2

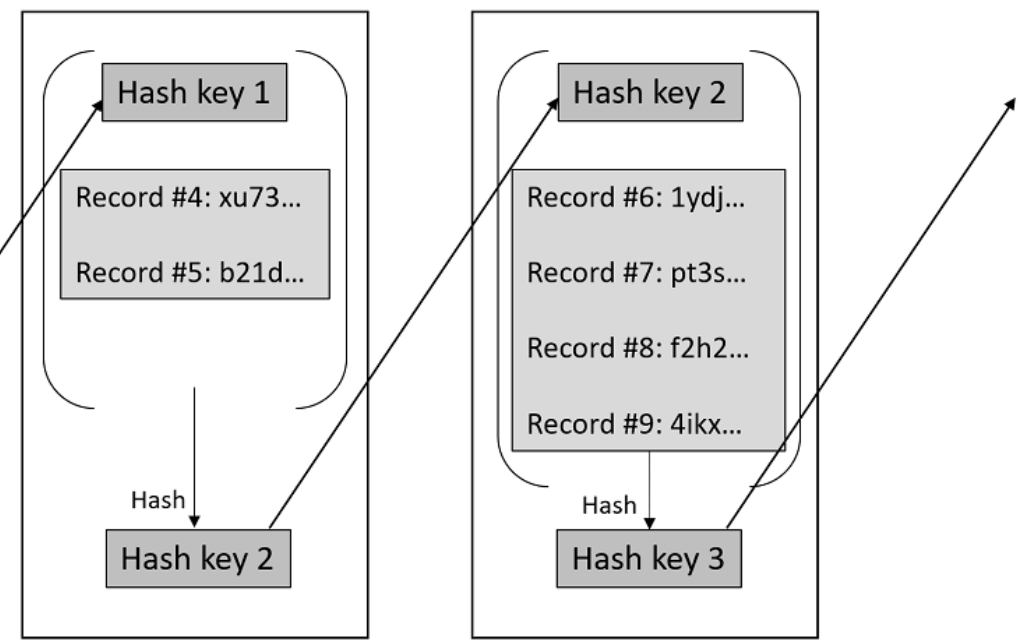

Blockchain 


\section{Types of Blockchains and Their Properties}

Before data can be added to a blockchain, its users need to agree or reach consensus. This is achieved through a consensus algorithm. A well-known consensus algorithm is the proof of work (PoW) algorithm. PoW is used in the Bitcoin and Ethereum blockchain network protocols [8,27]. In the PoW algorithm, users (also known as miners) compete in computational tasks to reach consensus. The winning miner of each block's task is usually given a reward [28].

Blockchains can be classified into the following three types, depending on which participants are allowed in the consensus algorithm [28]:

1. Public: anyone can participate in the consensus algorithm. Examples include Bitcoin and Ethereum [8,27].

2. Consortium: a select (or permissioned) group of entities can participate in the consensus algorithm. Examples include Hyperledger Fabric (HF), Quorum, and Corda [29-31].

3. Private: only a single entity operates the consensus algorithm and controls the addition of new data.
Public blockchains are sometimes referred to as permissionless blockchains, whereas consortium and private blockchains are collectively termed permissioned blockchains.

The three types of blockchains differ in the following properties:

1. Decentralization: unlike traditional databases that are owned by a specific entity, a decentralized blockchain can allow every user to own the data collectively. Using the illustration in Figure 1 as an example, a decentralized blockchain would contain all the records, but only one user owns records \#1, \#3, \#4, \#6, and \#8, and another user separately owns records \#2, \#5, \#7, and \#9.

2. Immutability: because of the underlying chain structure, once data have been added to the blockchain, they cannot be tampered with. Changing a record would alter the hash key and effectively cause a break in the chain.

3. Transparency (with privacy): the entire blockchain can be made publicly viewable while preserving privacy by masking each individual record using cryptography. To unmask one's own records, a private key is required.

Table 1 provides a summary of the different types of blockchains and their properties, with an example of each type in the health care setting.

Table 1. Comparison of public, consortium, and private blockchains.

\begin{tabular}{|c|c|c|c|}
\hline \multirow[t]{2}{*}{ Variables } & \multicolumn{3}{|l|}{ Type of blockchain } \\
\hline & Public & Consortium & Private \\
\hline $\begin{array}{l}\text { Participation in consensus } \\
\text { protocol }\end{array}$ & Anyone & $\begin{array}{l}\text { Select (or permissioned) group of enti- } \\
\text { ties }\end{array}$ & A single entity \\
\hline Decentralization & Yes & Partial & No \\
\hline Immutability & Tamperproof & Could be tampered with & Could be tampered with \\
\hline Transparency & Public & Can be public or restricted & Can be public or restricted \\
\hline $\begin{array}{l}\text { Example in health care } \\
\text { setting }\end{array}$ & $\begin{array}{l}\text { A transnational, open EMR }{ }^{\mathrm{a}} \text { system in } \\
\text { which anyone (eg, health care institu- } \\
\text { tions, patients) may choose to con- } \\
\text { tribute their own resources to maintain } \\
\text { health records of all patients who use } \\
\text { the EMR system }\end{array}$ & $\begin{array}{l}\text { A national EMR system in which select- } \\
\text { ed health care institutions collectively } \\
\text { maintain the health care records of their } \\
\text { patients }\end{array}$ & $\begin{array}{l}\text { An institution-based EMR system in } \\
\text { which only a single institution main- } \\
\text { tains the health records of its own pa- } \\
\text { tients }\end{array}$ \\
\hline
\end{tabular}

${ }^{\mathrm{a} E M R: ~ e l e c t r o n i c ~ m e d i c a l ~ r e c o r d . ~}$

\section{Scalability and Smart Contracts}

Finally, we will briefly explain the two concepts of scalability and smart contracts, which will be relevant to subsequent parts of this paper.

Scalability refers to the capacity of a blockchain to store and process transactions. It generally relates to the size and frequency of transactions a blockchain can handle. For example, Bitcoin's block size is limited to 1 megabyte, and each block is added every 10 minutes. This translates to a rate of approximately 7 transactions per second. Various solutions have been proposed to improve scalability. One such solution is to store data off-chain (instead of on-chain), and another solution is to use side-chains (linked to the main chain) to enable larger transaction volumes to be processed in parallel. Given that health care data are estimated to reach as much as 2314 exabytes generated yearly by 2020, it is crucial for almost all blockchain-based health care applications to achieve a certain level of scalability [32].

Smart contracts are programmable computer rules. Blockchain is a digital database that allows for the implementation of smart contracts, which can be automatically triggered to execute when predefined conditions are satisfied. For example, a smart contract can be programmed to issue tokens on the blockchain each time a user records his or her blood pressure. These tokens can then be used to pay for health care services. Such smart contracts can thus potentially be used to enable incentive structures to encourage certain positive user behaviors.

In this systematic review, particularly focused on the blockchain component of blockchain PHRs, we will pay particular attention 
to the (1) type of blockchain, (2) scalability solutions, and (3) smart contract-based incentive structures.

\section{Methods}

\section{Study Design}

While conducting and reporting this systematic literature review, the guidelines described in the PRISMA (Preferred Reporting Items for Systematic Reviews and Meta-analyses) statement were adopted [33]. This type of literature review was selected because the goal was to identify articles on blockchain PHRs and to summarize the current landscape, design choices, limitations, and future directions. Unlike a meta-analysis, this review did not require any data synthesis. Quality assessment was not performed because the intention was to achieve a collective understanding of the efforts and ideas rather than judging the quality of various blockchain PHRs.

The presented systematic review was carried out by defining the following activities:

1. Research questions

2. Search strategy

3. Article selection

4. Data abstraction

\section{Research Questions}

For this review, there were 3 research questions we aimed to address:

1. What are the current landscape and trends of blockchain PHRs in terms of interest groups, geography, and maturity level?

2. What were the key design decisions made for the blockchain PHRs described?

3. What are the current limitations faced by blockchain PHRs and future directions?

\section{Search Strategy}

The following search string was used: "blockchain" AND ("health record*" OR "medical record*" OR "*EHR*" OR “*EMR*" OR “*PHR*"). Articles in the following databases were searched: (1) ACM, (2) IEEE Xplore, (3) MEDLINE, (4) ScienceDirect, (5) Scopus, (6) SpringerLink, (7) Web of Science, and (8) Google Scholar. For databases whose search engines did not enable the use of wildcards, the search was widened to include abstracts and keywords, and Microsoft Excel was subsequently used to filter the returned list by applying the search string to the titles.

As the space is still in its infancy stage, Google Scholar was included as a search database to incorporate relevant gray literature in this review. This decision was supported by systematic reviews by Holbl et al [34] and Kuo et al [35] on blockchain in the health care domain, which had found valuable information residing in gray literature.

\section{Article Selection}

Once the articles were obtained, we applied the following inclusion and exclusion criteria to select articles for the final review. The inclusion criteria were as follows: a health record system that had (1) a patient-facing component and (2) used blockchain in its health record system. The exclusion criteria were as follows: (1) duplicate articles, (2) review articles, (3) articles that did not have full text available, and (4) articles whose full text was not in English.

The selection was performed in a stepwise manner. First, duplicate articles returned from multiple databases were excluded. Second, the titles of the articles were reviewed and those that were not relevant to the topic were discarded. Third, the abstracts of the articles were reviewed and those whose main focus was not on blockchains and EHR or PHR and those that were review articles were also discarded. Those that looked at EHRs at this stage were retained because some EHRs would have a patient-facing component but might not have been explicitly mentioned in the title or abstract. Finally, the full text was reviewed and those that did not have a PHR element in the EHR were discarded. At this stage, those that did not have full text available or whose full text was not in English were also excluded.

\section{Data Abstraction}

For data abstraction, a standardized data collection form was developed using Microsoft Excel. A full-text review of each selected study was performed independently by 3 reviewers who are knowledgeable about blockchain and health records. For discrepancies in the abstracted data, the reviewers performed a repeat review of the articles together to reach a consensus.

For the interest groups, author affiliations, publishers, and publications were used as a proxy. As this space is situated at the intersection of computer science (CS), engineering, and medicine, we classified the publications into either (1) CS or engineering, (2) medical, or (3) general. For maturity level, the classification used by Chukwu et al [12] was modified, and the projects were classified as concept/model/framework, prototypes, and pilots or implementations. A prototype was considered to have both a working front-end and back-end system, and a pilot or implementation had to be a product that was released for use in the real world. If an article described systems at multiple levels of maturity (eg, a framework and a prototype), only the more mature level described was abstracted.

Many design choices must be made when developing a blockchain PHR. To keep this review manageable, the review focused on high-level design decisions [36]. To ensure a comprehensive list of possible design parameters, the $P H R$ taxonomy proposed by Roehrs et al [37] and EHR in a Blockchain taxonomy proposed by Mayer et al [21] were used as starting points. Next, through a consensus-driven process of elimination, 10 design parameters were selected for abstraction. These were (1) blockchain type, (2) data storage, (3) scaling solution, (4) incentive smart contract, (5) PHR type, (6) data owner, (7) read and write ability, (8) semantic standards, (9) privacy standards, and (10) user interface (UI).

For limitations and future directions, the issues and areas for improvement brought up across the articles reviewed were identified, consolidated, and presented as a list of unique issues. We did not delve into a more in-depth analysis such as ranking the unique issues because the frequency of mention was not 
necessarily associated with importance or criticality. Moreover, the articles may not have fully listed all their limitations, as it was not their primary aim.
In total, 23 data elements were extracted from each article. Table 2 provides a complete list of the extracted data elements and a description of each element.

Table 2. List of data elements extracted from the selected articles.

\begin{tabular}{|c|c|}
\hline Types of data elements & Description \\
\hline \multicolumn{2}{|l|}{ General } \\
\hline Author & First author's last name \\
\hline Title & Title of the article \\
\hline Year & Publication year of the article \\
\hline Country & First author's affiliated country \\
\hline Type & Type of article (eg, journal article, conference paper, book chapter, and whitepaper) \\
\hline Publisher & Name of publisher of the article \\
\hline \multicolumn{2}{|l|}{ Blockchain } \\
\hline Name of blockchain PHR ${ }^{\mathrm{a}}$ & Name of the blockchain PHR (if any) \\
\hline Maturity & $\begin{array}{l}\text { Maturity level of the blockchain PHR described (ie, concept/framework, prototype, and pilot/implemen- } \\
\text { tation) }\end{array}$ \\
\hline Blockchain type & Type of blockchain (ie, public, consortium, private, or a combination) \\
\hline Blockchain name & Name of the blockchain used (if any) \\
\hline Data storage & Type of data storage mechanism (ie, on-chain, off-chain, or hybrid) \\
\hline Scaling solution & Type of scaling solution used in the blockchain PHR (if any) \\
\hline Incentive smart contract & Was a smart contract used to incentivize use of the blockchain PHR? (yes or no) \\
\hline \multicolumn{2}{|l|}{ PHR } \\
\hline PHR type & Type of PHR (ie, standalone or tethered to an existing EMR ${ }^{\mathrm{b}}$ system) \\
\hline Data owner & Party that owned the data from the blockchain PHR (ie, patient, provider, or both) \\
\hline Read-write access (for patients) & Was the patient given read and/or write access in the blockchain PHR? (yes or no) \\
\hline Read-write access (for providers) & Was the provider given read and/or write access in the blockchain PHR? (yes or no) \\
\hline Read-write access (for other parties) & Were other parties given read and/or write access in the blockchain PHR? (yes or no) \\
\hline Semantic standard & Type of semantic standard adopted (eg, HL- $7^{\mathrm{c}}$ and FHIR ${ }^{\mathrm{d}}$ ) \\
\hline Privacy standard & Type of privacy standard adopted (eg, HIPAA ${ }^{\mathrm{e}}$ and $\mathrm{GDPR}^{\mathrm{f}}$ ) \\
\hline User interface & Modality of accessing the blockchain PHR (ie, web, mobile, or desktop application) \\
\hline \multicolumn{2}{|l|}{ Additional } \\
\hline Limitations & Current limitations of the blockchain PHR \\
\hline Future directions & Future directions and opportunities described \\
\hline
\end{tabular}

${ }^{\mathrm{a} P H R}$ : personal health record.

${ }^{b}$ EMR: electronic medical record.

${ }^{\mathrm{c}} \mathrm{HL}-7$ : health level 7.

${ }^{\mathrm{d}}$ FHIR: Fast Healthcare Interoperability Resource.

${ }^{\mathrm{e}}$ HIPAA: Health Insurance Portability and Accountability Act.

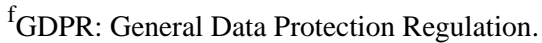

\section{Results}

\section{Overview of Articles}

The search performed on July 6, 2020, yielded 325 articles, of which 158 were unique articles. From the article selection process, 51 articles were selected for review. An additional 7 articles were added via snowballing (review of the references from the included articles) of the full texts screened (Figure 2). 
Figure 2. PRISMA (Preferred Reporting Items for Systematic Reviews and Meta-analyses) flow diagram of the article selection process. The title and author screen involved removing duplicate articles that had the same title and authors. The abstract screen involved reviewing article abstracts to remove review articles and those not related to blockchain and electronic health records. The full text screen involved reviewing the full articles to exclude those that did not meet the inclusion and exclusion criteria, and those whose full text was not available or in English. ACM: Association of Computing Machinery; EHR: electronic health record; IEEE: Institute of Electrical and Electronics Engineers; PHR: personal health record.

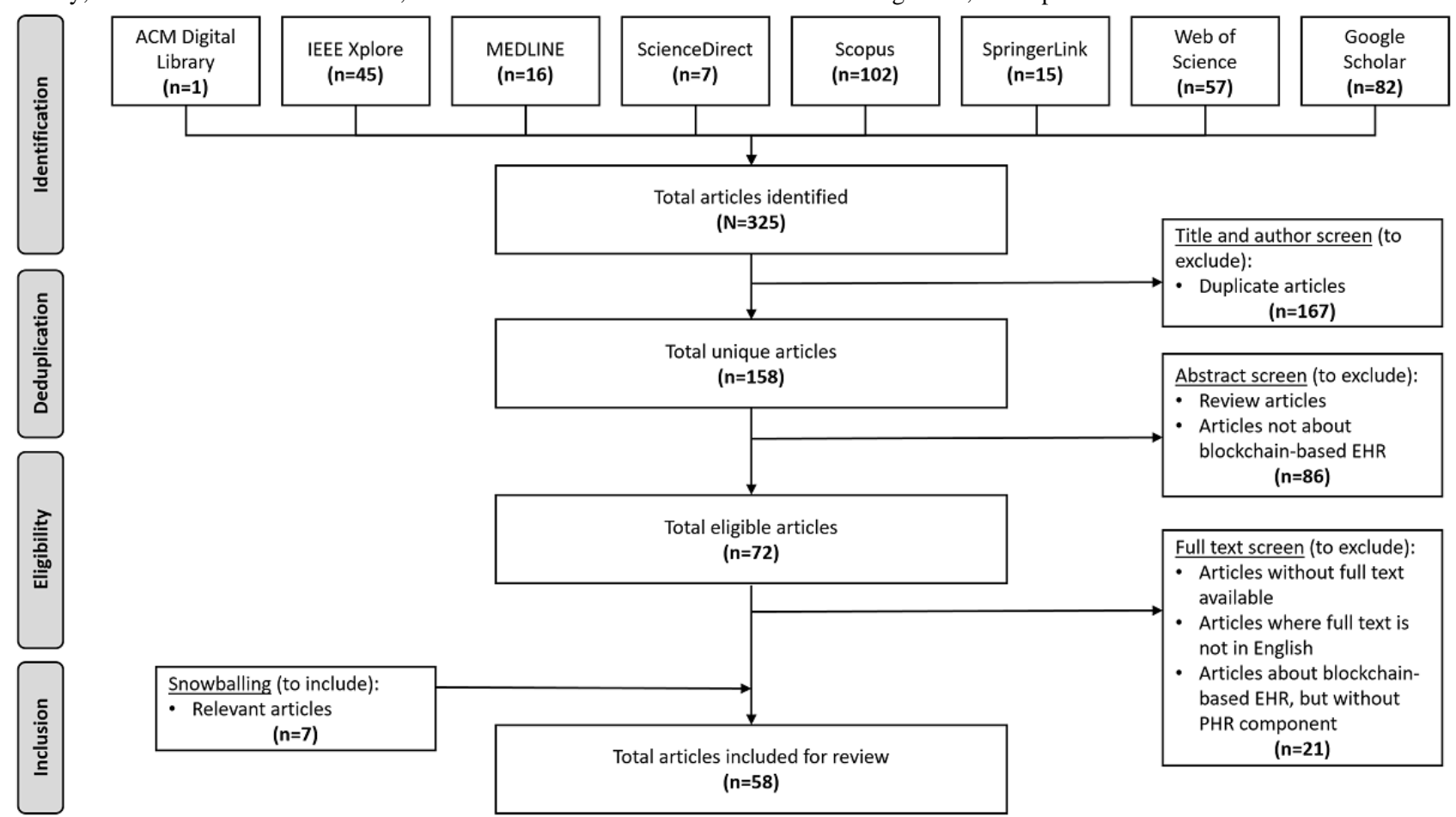

A total of 58 studies were included in the final review [17,19,37-92]. The complete list of articles, with identifiers used in this study, are presented in Table 3. The completed data collection form for these articles can be found in Multimedia
Appendix 1. An overview of the articles with the publication year, publisher, article type, country, and interest group is presented in Multimedia Appendix 2 [17,19,37-92]. 
Table 3. List of articles included in the final review.

\begin{tabular}{|c|c|c|}
\hline Article identifier & Authors & Article title \\
\hline A01 & Burniske [37] & How blockchain technology can enhance EHR ${ }^{\mathrm{a}}$ interoperability \\
\hline A02 & McFarlane et al [38] & Patientory: A Healthcare Peer-to-Peer EMR ${ }^{\mathrm{b}}$ Storage Network \\
\hline A03 & Roehrs et al [39] & OmniPHR: A distributed architecture model to integrate personal health records \\
\hline A04 & Badr et al [40] & Multi-tier blockchain framework for IoT ${ }^{\mathrm{c}}$-EHRs systems \\
\hline A05 & Boiani [41] & $\begin{array}{l}\text { Blockchain based electronic health record management for mass crisis scenarios: A feasibility } \\
\text { study }\end{array}$ \\
\hline A06 & Chen et al [42] & Blockchain-Based Medical Records Secure Storage and Medical Service Framework \\
\hline A07 & Dagher et al [43] & $\begin{array}{l}\text { Ancile: Privacy-preserving framework for access control and interoperability of electronic health } \\
\text { records using blockchain technology }\end{array}$ \\
\hline A08 & Dubovitskaya et al [44] & Secure and Trustable Electronic Medical Records Sharing using Blockchain \\
\hline A09 & Gebremedhin [45] & Blockchain as a Technology to Facilitate Privacy and Better Health Record Management \\
\hline A10 & Lippman et al [46] & MedRec: Patient Control of Medical Record Distribution \\
\hline A11 & Medicalchain [47] & Medicalchain \\
\hline A12 & Rouhani et al [48] & MEDICHAIN: A Secure Decentralized Medical Data Asset Management System \\
\hline A13 & $\begin{array}{l}\text { Thwin and Vasupongayya } \\
\text { [49] }\end{array}$ & Blockchain Based Secret-Data Sharing Model for Personal Health Record System \\
\hline A14 & Vora et al [50] & BHEEM $^{\mathrm{d}}$ : A Blockchain-Based Framework for Securing Electronic Health Records \\
\hline A15 & Zhang and Poslad [51] & $\begin{array}{l}\text { Blockchain Support for Flexible Queries with Granular Access Control to Electronic Medical } \\
\text { Records (EMR) }\end{array}$ \\
\hline A16 & Abouzahra [52] & Using blockchain technology to enhance the use of personal health records \\
\hline A17 & Alkhushayni et al, [53] & Blockchain technology applied to electronic health records \\
\hline A18 & Ray Chawdhuri [54] & Patient Privacy and Ownership of Electronic Health Records on a Blockchain \\
\hline A19 & Ciampi [55] & A Blockchain Architecture for the Italian EHR System \\
\hline $\mathrm{A} 20$ & Daraghmi et al [56] & $\begin{array}{l}\text { MedChain: A Design of Blockchain-Based System for Medical Records Access and Permissions } \\
\text { Management }\end{array}$ \\
\hline A 21 & Donawa et al [57] & Scaling Blockchains to Support Electronic Health Records for Hospital Systems \\
\hline A22 & Hang et al [58] & A novel EMR integrity management based on a medical blockchain platform in hospital \\
\hline A23 & Harika et al [59] & Blockchain technology for managing an architectural model of decentralized medical record \\
\hline A24 & Huang et al [60] & MedBloc: A Blockchain-Based Secure EHR System for Sharing and Accessing Medical Data \\
\hline A25 & Hylock and Zeng [61] & $\begin{array}{l}\text { A Blockchain Framework for Patient-Centered Health Records and Exchange (HealthChain): } \\
\text { Evaluation and Proof-of-Concept Study }\end{array}$ \\
\hline A26 & Jiang et al [62] & $\begin{array}{l}\text { Patients-Controlled Secure and Privacy-Preserving EHRs Sharing Scheme Based on Consortium } \\
\text { Blockchain }\end{array}$ \\
\hline A27 & Koushik et al [63] & Performance Analysis of BlockChain-based Medical Records Management System \\
\hline A28 & Lee [64] & PHR $^{\mathrm{e}}$ system using blockchain technology \\
\hline A29 & MediBloc [65] & MediBloc Technical Whitepaper \\
\hline A30 & MediLOT [66] & MediLOT Whitepaper \\
\hline A31 & Nchinda et al [67] & MedRec: A Network for Personal Information Distribution \\
\hline A32 & Nguyen et al [68] & Blockchain for Secure EHRs Sharing of Mobile Cloud Based E-Health Systems \\
\hline A33 & Park et al [17] & $\begin{array}{l}\text { Is Blockchain Technology Suitable for Managing Personal Health Records? Mixed-Methods } \\
\text { Study to Test Feasibility }\end{array}$ \\
\hline A34 & Rajput et al [69] & $\begin{array}{l}\text { EACMS: Emergency Access Control Management System for Personal Health Record Based } \\
\text { on Blockchain }\end{array}$ \\
\hline A35 & Reen et al [70] & Decentralized patient centric e-Health record management system using blockchain and IPFS \\
\hline
\end{tabular}




\begin{tabular}{|c|c|c|}
\hline Article identifier & Authors & Article title \\
\hline A36 & Sangeetha [71] & Electronic Health Record System using Blockchain \\
\hline A37 & Shahnaz et al [72] & Using Blockchain for Electronic Health Records \\
\hline A38 & Shekhawat [73] & Cloud-chain: Revamp Health Record System Using Blockchain \\
\hline A39 & $\begin{array}{l}\text { Thwin and Vasupongayya } \\
\text { [74] }\end{array}$ & Blockchain-Based Access Control Model to Preserve Privacy for Personal Health Record Systems \\
\hline $\mathrm{A} 40$ & Tian [75] & Blockchain-based secure medical record sharing system \\
\hline A41 & Toshniwal et al [76] & PACEX: Patient-centric EMR exchange in Healthcare Systems using Blockchain \\
\hline A42 & Wang et al [77] & Blockchain-Based Personal Health Records Sharing Scheme With Data Integrity Verifiable \\
\hline A43 & Wang et al [78] & Cloud-Assisted EHR Sharing with Security and Privacy Preservation via Consortium Blockchain \\
\hline A44 & Wu and Du [79] & Electronic medical record security sharing model based on blockchain \\
\hline A45 & Al Goni et al [80] & $\begin{array}{l}\text { A P2P Optimistic Fair-Exchange Scheme for Personal Health Records Using Blockchain Tech- } \\
\text { nology }\end{array}$ \\
\hline A46 & $\begin{array}{l}\text { Arunkumar and Kousalya } \\
\text { [81] }\end{array}$ & $\begin{array}{l}\text { Blockchain-Based Decentralized and Secure Lightweight E-Health System for Electronic Health } \\
\text { Records }\end{array}$ \\
\hline A47 & Aswin et al [82] & Design of AYUSH: A blockchain-based health record management system \\
\hline A48 & Cao et al [83] & $\begin{array}{l}\text { Hybrid blockchain-based privacy-preserving electronic medical records sharing scheme across } \\
\text { medical information control system }\end{array}$ \\
\hline A49 & Charanya et al [84] & Sefra: A secure framework to manage eHealth records using blockchain technology \\
\hline A50 & Kavathekar and Patil [85] & Data sharing and privacy-preserving of medical records using blockchain \\
\hline A51 & Kim et al [86] & Design of Secure Protocol for Cloud-Assisted Electronic Health Record System Using Blockchain \\
\hline A52 & Kung et al [87] & Personal Health Record in FHIR ${ }^{f}$ Format Based on Blockchain Architecture \\
\hline A53 & Lee et al [19] & $\begin{array}{l}\text { An Architecture and Management Platform for Blockchain-Based Personal Health Record Ex- } \\
\text { change: Development and Usability Study }\end{array}$ \\
\hline A54 & Sharma et al [88] & $\begin{array}{l}\text { Secure Cloud Storage Architecture for Digital Medical Record in Cloud Environment using } \\
\text { Blockchain }\end{array}$ \\
\hline A55 & $\begin{array}{l}\text { Sharma and Balamurugan } \\
\text { [89] }\end{array}$ & Preserving the Privacy of Electronic Health Records using Blockchain \\
\hline A56 & Tith et al [90] & $\begin{array}{l}\text { Application of Blockchain to Maintaining Patient Records in Electronic Health Record for En- } \\
\text { hanced Privacy, Scalability, and Availability }\end{array}$ \\
\hline A57 & Verdonck and Poels [91] & $\begin{array}{l}\text { Architecture and value analysis of a blockchain-based electronic health record permission man- } \\
\text { agement system }\end{array}$ \\
\hline A58 & Wu et al [92] & Secure Personal Health Records Sharing Based on Blockchain and IPFS ${ }^{\mathrm{g}}$ \\
\hline
\end{tabular}

${ }^{a}$ EHR: electronic health record.

${ }^{b}$ EMR: electronic medical record.

${ }^{\mathrm{c}}$ IoT: internet of things.

${ }^{d}$ BHEEM: Blockchain-based framework for efficient storage and maintenance of electronic health records

${ }^{\text {e}}$ PHR: personal health record.

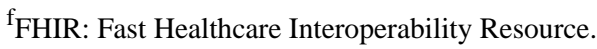

gIPFS: Interplanetary File System.

\section{Current Landscape and Trends of Blockchain PHRs}

\section{Interest Group}

The level of academic interest in the space has been rising, supported by an increasing trend in the number of published articles since 2016. In terms of interest groups, 45 articles were CS-or engineering-related publications or from CS- or engineering-related authors. Seven were published in medical journals, all of which were related to medical informatics. Of the 6 remaining articles that were classified as General, 5 were whitepapers. The articles from the CS or engineering interest group showed a sharp rise from 2017 to 2019 and may have started to plateau, whereas those from medical journals have been following a gradual, steady increase since 2016 (Figure $3)$. 
Figure 3. Trend of blockchain personal health record articles by interest group. The trend from 2019 to 2020 (represented by dashed lines) is a projection because only data from the first half of the year 2020 was available at the time of the search. Count refers to the number of articles published in that year.

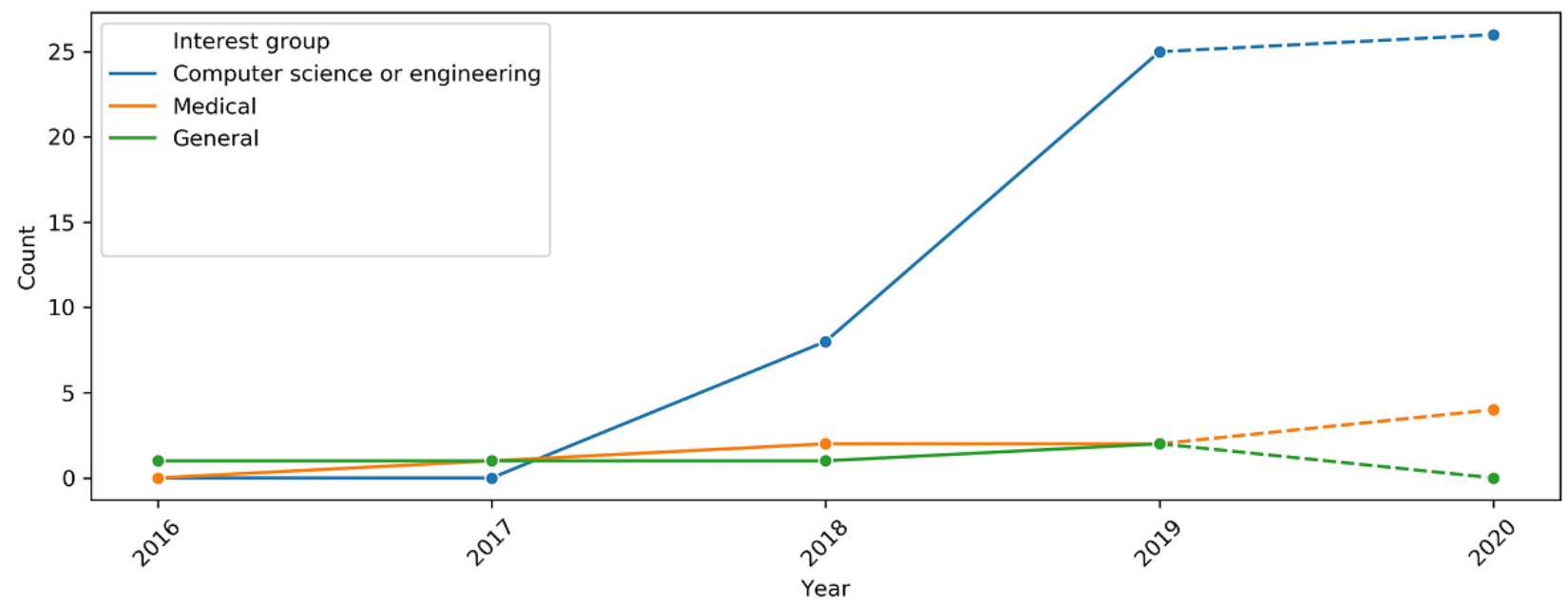

\section{Geographic Distribution}

The articles originated from 23 different countries. The majority were from India $(n=13)$, United States $(n=9)$, China $(n=8)$, and South Korea $(n=5)$, with Canada, Switzerland, Taiwan, and Thailand having 2 articles each and the remaining countries having 1 article each (Figure 4). Although the research interest in blockchain PHR is multinational, there clearly are a few countries that are leading the pack. Among these leading countries, there has been an increasing number of publications from India over the years, whereas China, South Korea, and the United States have shown a slowing trend. Apart from these countries, the aggregated output from the rest of the countries is also increasing (Figure 5).

Figure 4. Distribution of articles published by geography. The number of articles refers to the total number of articles selected for the final review.

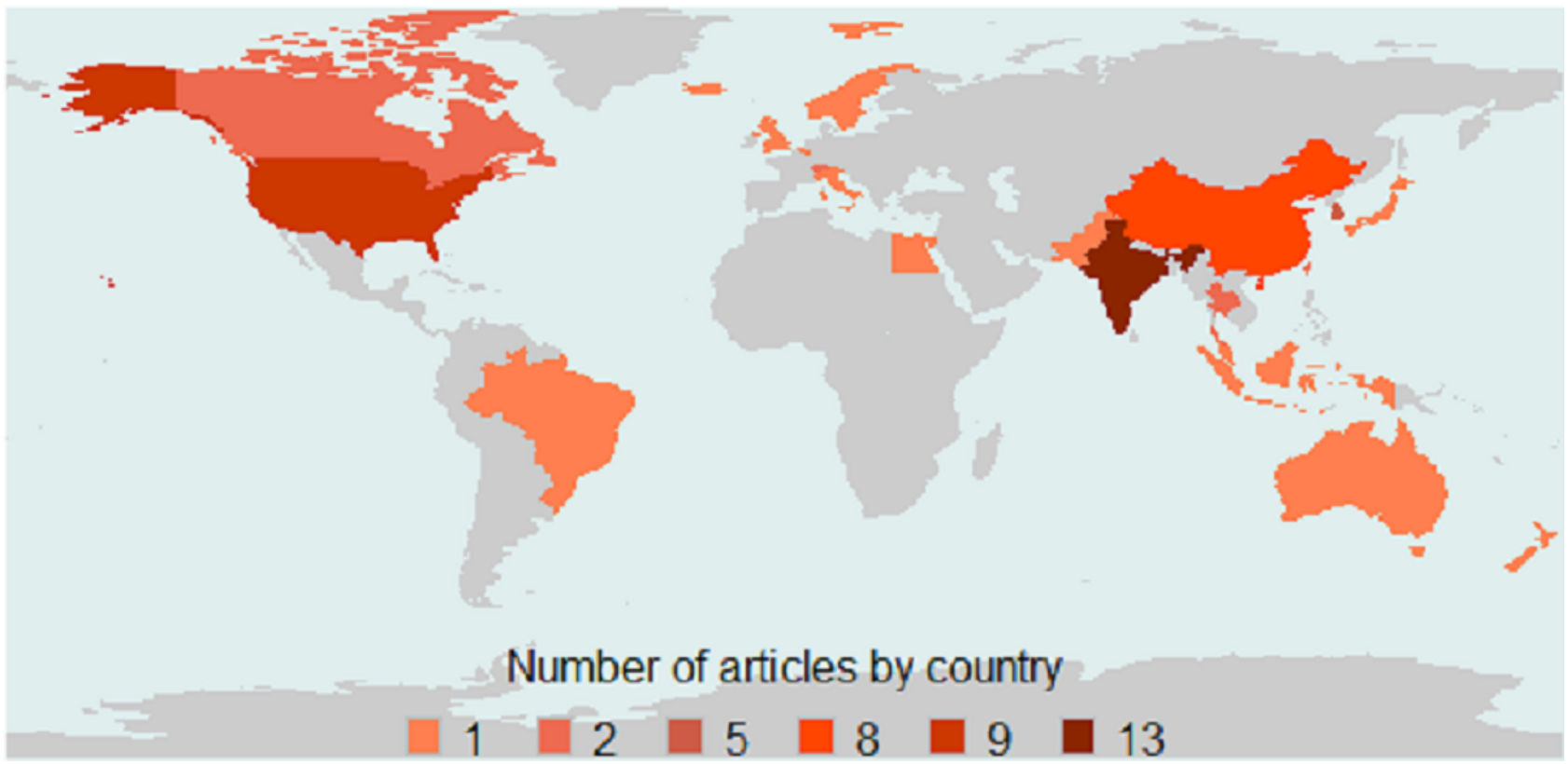


Figure 5. Trend of blockchain personal health record articles by country. Only countries with 5 or more articles in the final review were plotted individually. The other countries were grouped under an Others category. The trend from 2019 to 2020 (represented by dashed lines) is a projection because only data from the first half of the year 2020 was available at the time of the search. Count refers to the number of articles published in that year.

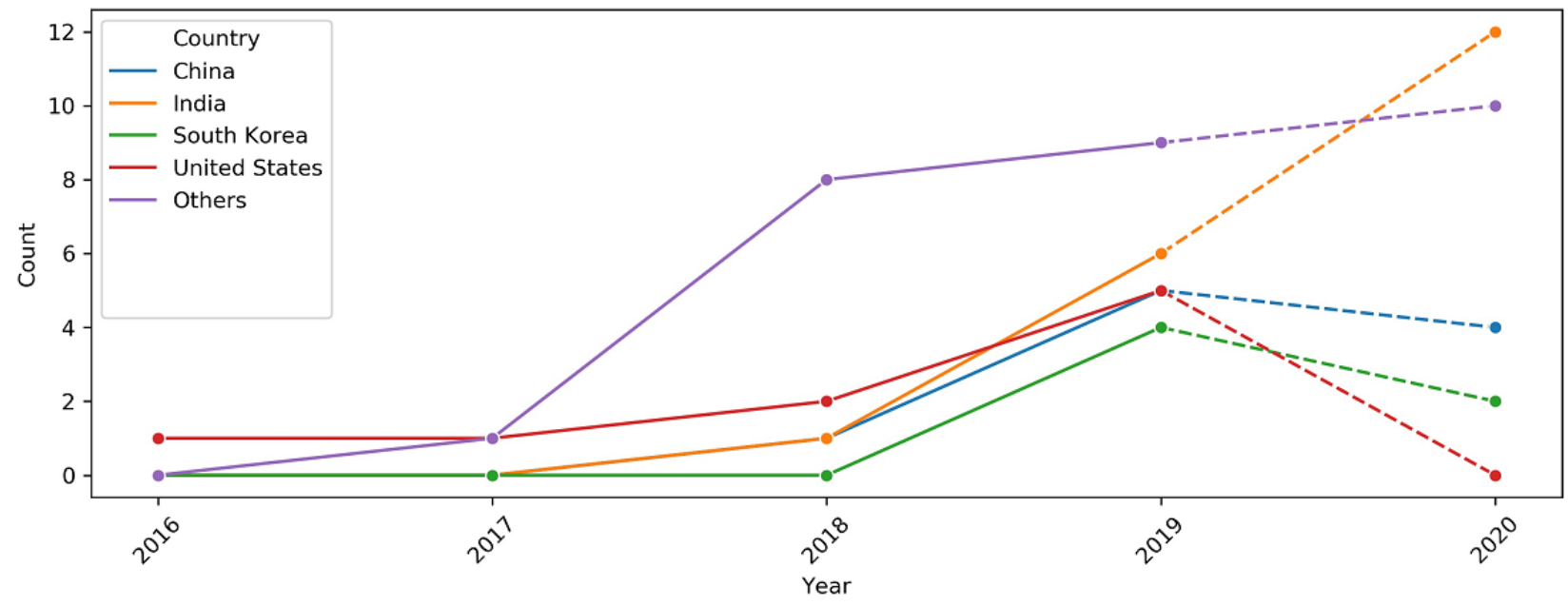

\section{Maturity Level}

The blockchain PHR space is maturing, with the proportion of articles describing prototypes showing an upward trend (Figure 6). In addition, the first paper to describe an implementation was also published in the first half of 2020 by Lee et al [19]. Their blockchain PHR implementation was deployed across Southeast Asia via an information network and became the first PHR management platform for cross-regional medical data exchange.

Figure 6. Trend of blockchain personal health record maturity. Note that the trend from 2019 to 2020 (represented by dashed lines) is a projection because only data from the first half of the year 2020 was available at the time of search. Count refers to the number of articles published in that year (2018).

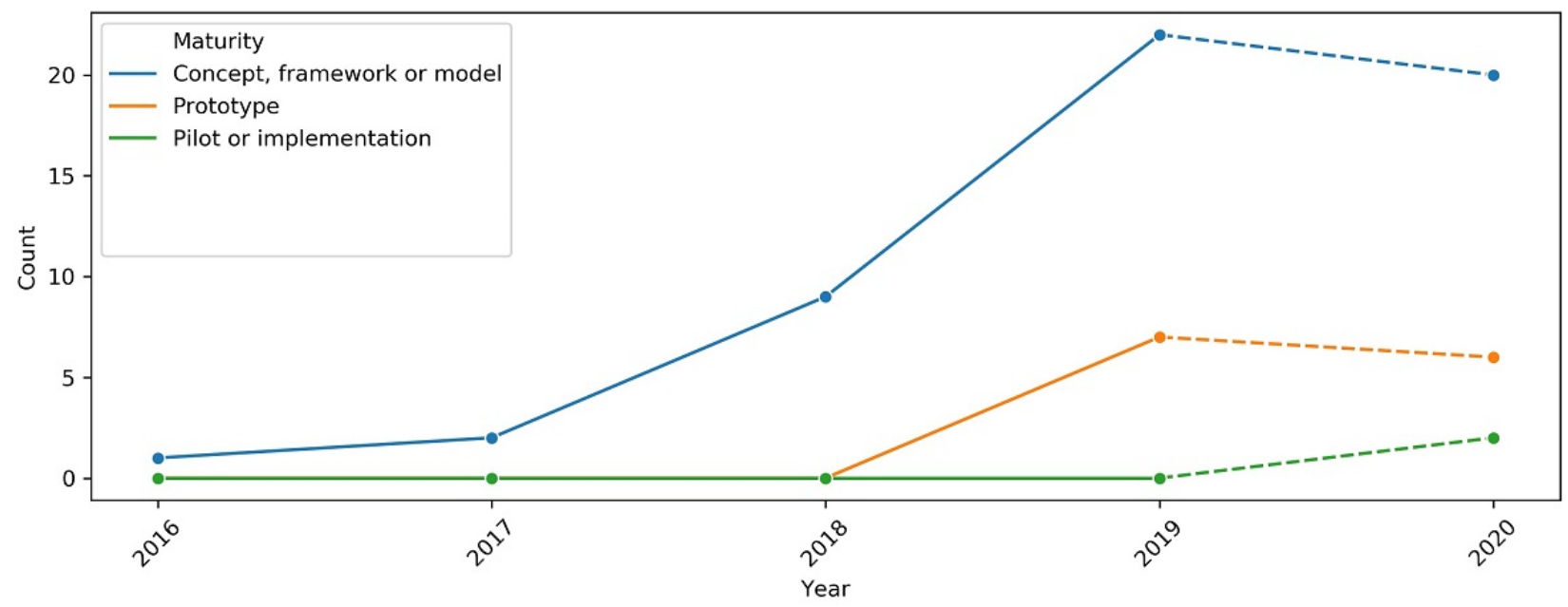

\section{Key Design Choices for Blockchain PHRs}

\section{Blockchain Attributes}

Most blockchain PHRs are described using a private $(n=24)$ or consortium $(n=22)$ blockchain, whereas 4 others used a public-permissioned hybrid design. Only 4 cases of using a public blockchain were described. In the remaining 4 cases, the blockchain type was not clearly stated. An Ethereum-based blockchain was the most commonly used $(n=26)$, with HF being the next most common $(n=20)$. Among these, 3 articles used both Ethereum and HF.

For data storage, the majority used off-chain data storage $(n=40)$, 14 stored EHR data on-chain, and 4 described hybrid data storage. For off-chain storage, 10 articles, all from 2019 onward, used the Interplanetary File System (IPFS). In terms of other scaling solutions, 9 articles considered new consensus algorithms such as Proof-of-Authority, 4 used a tiered-chain architecture, and 1 used both side-chain and algorithmic methods to improve the blockchain scaling capacity.

Among the articles, 5 described an incentive structure in the blockchain PHR using smart contracts. Four of these were whitepapers, which proposed incentivizing stakeholders through the issuing of tokens (digital currency of value) from smart contracts. In these cases, once an action warranting compensation had taken place, the smart contract automatically triggered the issuance of tokens. Table 4 provides additional 
details of the tokens and how they can be earned and used as part of the incentive structure. Unlike the others, Daraghmi et al [56] proposed a novel, nonmonetary incentive. Their system kept score using degrees based on the effort in maintaining the quality of records and creating new blocks. Those with higher degrees would have a lower probability of performing the computation task of creating new blocks. In this way, it is meant to achieve fairness and sustainability of the system.

Table 4. Incentive structure proposed by blockchain personal health record systems.

\begin{tabular}{|c|c|c|c|c|}
\hline Article identifier & Token name & Party compensated & Compensation & Token use \\
\hline A02 & $\begin{array}{l}\text { Patientory issued to- } \\
\text { kens }\end{array}$ & Provider & $\begin{array}{l}\text { On the basis of how effective } \\
\text { provider ensures improvement in } \\
\text { care quality and outcomes }\end{array}$ & $\begin{array}{l}\text { - Renting storage space on the plat- } \\
\text { - } \quad \text { Execution of smart contracts }\end{array}$ \\
\hline A11 & MedToken & Patients & $\begin{array}{l}\text { - Sharing of personal health data on } \\
\text { health care data marketplace }\end{array}$ & $\begin{array}{l}\text { - Lower insurance premiums } \\
\text { - Payment for use of applications (eg, } \\
\text { tele-consultations) }\end{array}$ \\
\hline A 29 & MediBloc coin & Provider & $\begin{array}{l}\text { - Performing computational task of } \\
\text { producing blocks }\end{array}$ & - Tradable for monetary value \\
\hline A30 & LOT $^{\mathrm{a}}$ token & Patients & $\begin{array}{l}\text { - Contribute data } \\
\text { - Compliance to health care recom- } \\
\text { mendations }\end{array}$ & 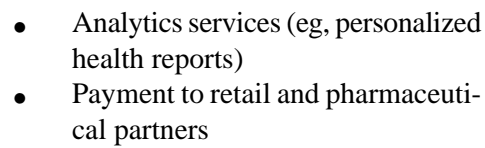 \\
\hline
\end{tabular}

${ }^{a}$ LOT: token used in the MediLOT system.

\section{PHR Attributes}

A total of 18 articles described a tethered blockchain PHR that interfaced with an existing electronic medical record (EMR) system. All of these were of the Concept/Framework/Model maturity level. Those that were prototypes, pilots, or implementations were all standalone PHR systems.

In the majority $(n=45)$ of the articles, the patient was the data owner. Of the remaining articles, providers were data owners in 9 of them, whereas 2 had both patients and providers as owners. It was unclear who the data owner was in the last 2 articles.

In most articles, both patients and providers had read and write abilities. Most blockchain PHRs granted providers with both read and write abilities $(n=40)$, and only 4 blockchain PHRs did not grant providers any read or write abilities. Table 5 is a matrix representing the distribution of read and write capabilities for patients and doctors among the various articles and article codes refer to article identifier in Table 3.

Table 5. Matrix of various read and write models among the blockchain personal health records reviewed.

\begin{tabular}{llll}
\hline Provider & Patient & & Read and write \\
\hline Read only & Read only & Write only & A04, A15, A32, A42, A48, A50, A52, \\
& $-{ }^{\mathrm{a}}$ & - & - \\
Write only & A07, A14, A18, A31 & - & A02, A03, A06, A09, A11, A21, A22, \\
Read and write & A01, A05, A08, A10, A12, A17, A19, A25, A51 & A26, A34, A35, A37, A38, A39, A44, \\
& A20, A23, A24, A27, A28, A30, A33, & A45, A46, A53, A54, A55, A57 \\
& A40, A41, A43, A47, A49, A56 & A13, A29, A36 \\
\hline
\end{tabular}

${ }^{\mathrm{a}}$ Not available.

Most articles did not mention the adoption of any semantic standard. For those that did, the 2 standards mentioned were Fast Healthcare Interoperability Resource (FHIR) and health level 7 (HL-7) in 5 and 2 articles, respectively. Similarly, most did not mention adopting any privacy standards. For those that did, 4 mentioned compliance with the Health Insurance Portability and Accountability Act (HIPAA), 1 with the General Data Protection Regulation (GDPR), and 1 with both the HIPAA and GDPR.
Among the blockchain PHRs that were either prototypes or implementations, 9 developed a web UI, whereas 2 had both a mobile phone application UI and a desktop UI.

\section{Current Limitations of and Future Directions for Blockchain PHRs}

\section{Current Limitations}

Most of the current limitations can be grouped into 1 of the following 3 main categories: (1) scalability, (2) privacy, and 
(3) usability. Scalability issues pertained to the inability of blockchain PHR to store large file sizes such as medical images $[44,53,54]$ or to the slowness in confirming transactions, especially with the incorporation of streaming data from internet of things devices [45,76].

The inability of blockchain PHRs to ensure full privacy has been highlighted in a few articles. Although records on the blockchain are encrypted, there are possible means to infer the information, such as through blockchain analysis [17,43,54]. Another privacy issue raised was the inability to erase one's records, as blockchains are inherently immutable [17,70]. This limitation would make it difficult for blockchain PHRs to comply with privacy regulations such as the GDPR, which stipulates data subjects' right to erasure (Article 17 of the GDPR).

One of the usability limitations was the affordability of the blockchain PHR, as each transaction typically required users to pay a transaction fee $[45,71]$. Another practical usability issue described by Charanya et al [84] was that, unlike conventional PHRs that had password recovery mechanisms, patients would not be able to access their records if they lost their private keys on blockchain PHRs. Incapacitated or unconscious patients also present a similar problem with blockchain PHRs that do not have built-in access control when emergency health care providers would need permission to access records.
Apart from these 3 main categories, there were other limitations inherent to certain types of popular blockchains such as Ethereum. For example, Gebremedhin [45] highlighted that Solidity (Ethereum's programming language) was unable to implement nested string data types, whereas Kung et al [86] mentioned the need to batch upload data in a certain file format as a limitation of their Ethereum-based PHR.

\section{Future Directions}

The current limitations provide direction to some future work areas for blockchain PHRs. Scalability solutions have already been studied and experimented on, such as Proof-of-Authority and the novel Byzanthine fault tolerance (BFT) consensus mechanisms [44,56,67]. Other methods include enhancing the blockchain architecture through tiered-chain [40,64] or side-chain structures [57]. Although privacy solutions were more limited in our review, we came across one by Reen et al [70] who proposed storing InterPlantary Naming System records instead of the conventional hash of the medical records directly on the blockchain. In this way, users may retain the ability to revoke access to the record if desired.

Many suggestions have been made to improve the usability of the system. These suggestions could be grouped into (1) user experience, (2) integration with existing systems, and (3) compliance with regulations and development of governance processes. Table 6 summarizes the suggestions proposed in the articles reviewed.

Table 6. Suggestions for improving blockchain personal health record usability from the selected articles.

\begin{tabular}{|c|c|}
\hline Suggestion & Article identifiers \\
\hline \multicolumn{2}{|l|}{ User experience } \\
\hline Improving user interface of blockchain PHRs ${ }^{\mathrm{a}}$ & A10, A31, A55 \\
\hline Biometric user authentication & A40 \\
\hline Allowing next-of-kin or caregiver to access records if patient grants access or is incapable of self-access & A40 \\
\hline Incorporating incentives for users & A56 \\
\hline Incorporating analytics capabilities for personal health insights and management & A32, A53 \\
\hline Adding on payment functions for health care services & A37, A55 \\
\hline \multicolumn{2}{|l|}{ Integration with existing systems } \\
\hline Integrating with existing $\mathrm{EMR}^{\mathrm{b}}$ systems & A07, A08, A19, A20, A52, \\
\hline Integrating with IoT $^{\mathrm{c}}$ devices & A32 \\
\hline Integrating with open, public blockchain systems & A17, A18, A33 \\
\hline \multicolumn{2}{|l|}{ Compliance with regulations and development of governance processes } \\
\hline Complying with regulations on health care data privacy & A07, A18 \\
\hline Developing governance processes for the blockchain PHRs & A38 \\
\hline
\end{tabular}

${ }^{\mathrm{a}} \mathrm{PHR}$ : personal health record.

${ }^{b}$ EMR: electronic medical record.

${ }^{\mathrm{c}} \mathrm{IoT}$ : internet of things.

Apart from improving usability, another aspect of future work is the validation of blockchain PHRs. Among the areas for validation, several articles suggested data validation when data were transferred to off-chain storage [77], security validation $[48,58,79]$, and real-world validation in terms of cost-effectiveness [52,53,71]. Validating these components 
would be relevant to obtain stakeholder and user confidence in deciding where to implement and adopt blockchain PHRs.

\section{Discussion}

\section{Principal Findings}

In this first ever systematic review on blockchain PHRs, we adopted a broad search strategy across medical and CS and engineering databases and included gray literature. We focused on the scope of blockchain PHRs to allow for more targeted data abstraction. Through our study, we found that there was a growing interest in blockchain PHRs and that the space has been steadily maturing over the past few years, albeit still much in the conceptual stage. As the space is still fairly new, a lion's share of the research and innovation has been happening at the technical level to discover new ways to solve problems. This is evidenced by the overwhelming proportion of articles that have come from the CS and engineering domain.

One of the major areas regarding blockchain PHRs that is still undergoing much research is scalability. We came across a few ideas such as Proof-of-Authority, novel BFT consensus mechanisms, and other modified blockchain architectures such as tiered-chains and side-chains [40,44,56,57,64,67]. Apart from blockchain PHR teams working on this, the space may also benefit from parallel innovations from the larger blockchain ecosystem. As Ethereum is looking forward to a new version release (version 2), it is considering various scaling solutions, of which rollups is a strong contender [93]. Rollups solution essentially involves keeping transaction data on-chain while pushing the computational load off-chain. If adopted into Ethereum 2.0, this could automatically benefit many Ethereum-based PHRs.

Although some areas are actively evolving, others are beginning to consolidate. As found in other systematic reviews, most blockchain PHR project teams have gravitated toward Ethereum and $\mathrm{HF}$ as their blockchains of choice [22]. In addition, in terms of data storage, we see more projects opting for IPFS as a complementary off-chain data store for their blockchain PHRs $[68,72,83,92]$. Outside of this review, we are also aware that there are efforts happening in other public blockchains. An example is NEO, whose core developers are developing a similarly distributed, decentralized object storage network known as NEO file storage system (NeoFS), which will seamlessly integrate with its native blockchain $[94,95]$. We did not come across any NEO-based PHRs in this review. NeoFS could potentially be a game changer, so it would be interesting to track its development in this area.

In this review, we also identified some current limitations that blockchain PHRs need to address. We broadly classified them into scalability, privacy, and usability limitations. In addition to identifying the current limitations, this review also revealed some possible solutions. For example, to address the privacy issue of inferring information from chain analysis, Ray Chawdhuri [54] introduced zero-knowledge provable mixing, whereas Park et al [17] proposed the zero-knowledge succinct non-interactive argument of knowledge technique. Another example is the solution of using biometric authentication mentioned by Tian [75] to address the issues of verifiable user authentication and patients losing their private keys. Medicalchain has also described an emergency bracelet that can be scanned, giving access to essential health information in unconscious patients who are unable to access their private keys [47].

The first blockchain PHR has already been piloted, and this will undoubtedly augur a move of the space toward deployment [19]. With this in mind, blockchain PHRs will need to comply with the privacy standards within the jurisdictions they intend to become operational. In addition, to enable integration with existing health care EMR systems, it is necessary to design blockchain PHRs that follow established semantic standards such as HL-7 and FHIR. Looking further ahead, to realize true decentralization, it may be necessary to consider building a PHR atop public blockchains.

Finally, in terms of geographic interest, we found that although interest in blockchain PHR was multinational, there were obvious leaders in this space. Looking deeper among the leading countries, we noticed that since 2018 there has been an increase in publications from India, whereas those from China, South Korea, and the United States started to level off or decrease. A possible reason for this could be that in 2017, in the midst of an initial coin offering (ICO) fever that drove unusually high interest in blockchain, the latter 3 countries' relevant authorities had issued bans or indicated legal restrictions on ICO activities with stiff penalties [96-98]. This may suggest further research into the different factors, including sociopolitical, economic, and cultural factors, which could significantly impact the development of this space. In terms of interest groups, our findings should also provide a sense of where most of the developments are occurring, and this may guide government and private sector funders in their allocation of resources.

\section{Limitations}

We acknowledge that this review is not exhaustive and that there are many other areas that were excluded. These areas include other smart contract uses, performance evaluation, and the type of vocabulary standard such as Systematized Nomenclature of Medicine Clinical Terms, 10th revision of the International Classification of Diseases, and Logical Observation Identifiers Names and Codes. We also recognize that greater detail about the read and write models could be studied, such as their validity periods and whether other stakeholders (eg, researchers and insurance companies) were given access. Future reviews should consider delving deeper into these areas.

Furthermore, despite our best efforts to capture as much material available as possible, we are aware that the exclusion of articles whose full text was not in English would have limited the scope of this review. In addition, there may also be other developments in this space that have not been made publicly available for commercial or other reasons.

\section{Conclusions}

This cross-disciplinary systematic review on the blockchain PHR space has revealed that as of now, much of the development is still in the conceptual stage. However, there is a trend of growth and maturation. We believe that this provides 
consolidated evidence for researchers to continue following this space and, more optimistically, to spur them to contribute ideas and efforts to accelerate its development. Those in the medical informatics community will undoubtedly play an increasingly larger role in the development and implementation of blockchain
PHRs, especially when the need to integrate with EMR systems and adopt health care data standards becomes more prominent. In addition, as the first systematic review covering blockchain PHRs, we expect this to be an important basis for subsequent reviews to track how the space has progressed in the future.

\section{Acknowledgments}

The authors would like to thank their families and work organizations—SingHealth Polyclinics, SingHealth Community Hospitals, and the National University Hospital—for their support.

\section{Authors' Contributions}

AF had the original idea for this study. AF, MT, and CT designed the review. MT obtained the relevant articles. AF, TT, and MT reviewed the articles and abstracted the data. AF wrote the first draft of this paper, and all the authors subsequently assisted in revising the work and have approved the final version.

\section{Conflicts of Interest}

The authors did not receive any funding for this work and declare no conflicts of interest. However, the authors would like to highlight that MT is the cofounder of MediLOT, which published one of the articles reviewed in this paper.

\section{Multimedia Appendix 1}

List of articles with data abstracted.

[XLSX File (Microsoft Excel File), 29 KB-Multimedia Appendix 1]

\section{Multimedia Appendix 2}

Overview of the articles with the article identifier, publication year, publisher, type of article, country and interest group. [DOCX File, 15 KB-Multimedia Appendix 2]

\section{References}

1. Tang PC, Ash JS, Bates DW, Overhage JM, Sands DZ. Personal health records: definitions, benefits, and strategies for overcoming barriers to adoption. J Am Med Inform Assoc 2006 Mar;13(2):121-126 [FREE Full text] [doi:

10.1197/jamia.M2025] [Medline: 16357345]

2. Price M, Bellwood P, Kitson N, Davies I, Weber J, Lau F. Conditions potentially sensitive to a personal health record (PHR) intervention, a systematic review. BMC Med Inform Decis Mak 2015;15:32 [FREE Full text] [doi: 10.1186/s12911-015-0159-1] [Medline: 25927384]

3. Andrikopoulou E, Scott P, Herrera H, Good A. What are the important design features of personal health records to improve medication adherence for patients with long-term conditions? A systematic literature review. BMJ Open 2019 Sep 26;9(9):e028628. [doi: 10.1136/bmjopen-2018-028628]

4. Dameff C, Clay B, Longhurst CA. Personal Health Records: More Promising in the Smartphone Era? JAMA 2019 Jan 29;321(4):339-340. [doi: 10.1001/jama.2018.20434] [Medline: 30633300]

5. Alanazi A, Anazi YA. The Challenges in Personal Health Record Adoption. Journal of Healthcare Management 2019;64(2):104-109. [doi: 10.1097/jhm-d-17-00191]

6. Hossain MM, Hong YA. Trends and characteristics of protected health information breaches in the United States. 2019 Presented at: AMIA Annu Symp Proc. 2020; 2019; Washington p. 1081-1090.

7. Abd-alrazaq AA, Bewick BM, Farragher T, Gardner P. Factors that affect the use of electronic personal health records among patients: A systematic review. International Journal of Medical Informatics 2019 Jun;126:164-175. [doi: 10.1016/j.ijmedinf.2019.03.014]

8. Nakamoto S. Bitcoin: A Peer-to-Peer Electronic Cash System. SSRN Journal 2008:1-9. [doi: 10.2139/ssrn.3440802]

9. Kane E. Is Blockchain a General Purpose Technology? SSRN Journal 2017 Mar 11:1-27. [doi: 10.2139/ssrn.2932585]

10. Tapscott D, Tapscott A. Blockchain Revolution: How the Technology Behind Bitcoin and Other Cryptocurrencies Is Changing the World. Blockchain Revolution: Penguin Random House; 2018.

11. Agbo C, Mahmoud Q, Eklund J. Blockchain Technology in Healthcare: A Systematic Review. Healthcare 2019 Apr 04;7(2):56. [doi: 10.3390/healthcare7020056]

12. Chukwu E, Garg L. A Systematic Review of Blockchain in Healthcare: Frameworks, Prototypes, and Implementations. IEEE Access 2020;8:21196-21214. [doi: 10.1109/access.2020.2969881]

13. Drosatos G, Kaldoudi E. Blockchain Applications in the Biomedical Domain: A Scoping Review. Computational and Structural Biotechnology Journal 2019;17:229-240. [doi: 10.1016/j.csbj.2019.01.010] 
14. Hasselgren A, Kralevska K, Gligoroski D, Pedersen SA, Faxvaag A. Blockchain in healthcare and health sciences-A scoping review. International Journal of Medical Informatics 2020 Feb;134:104040. [doi: 10.1016/j.ijmedinf.2019.104040]

15. Adelmeyer M, Meier P, Teuteberg F. Security and Privacy of Personal Health Records in Cloud Computing Environments - An Experimental Exploration of the Impact of Storage Solutions and Data Breaches. In: Security and Privacy of Personal Health Records in Cloud Computing Environments - An Experimental Exploration of the Impact of Storage Solutions and Data Breaches.: AIS Electronic Library; 2019 Presented at: Wirtschaftsinformatik 2019; 23-Feb-2019 to 29-Feb-2019; Siegen.

16. Xuan S, Zheng L, Chung I, Wang W, Man D, Du X, et al. An incentive mechanism for data sharing based on blockchain with smart contracts. Computers \& Electrical Engineering 2020 May;83:106587. [doi: 10.1016/j.compeleceng.2020.106587]

17. Park YR, Lee E, Na W, Park S, Lee Y, Lee J. Is Blockchain Technology Suitable for Managing Personal Health Records? Mixed-Methods Study to Test Feasibility. J Med Internet Res 2019 Feb 08;21(2):e12533 [FREE Full text] [doi:

10.2196/12533] [Medline: 30735142]

18. Roehrs A, da Costa CA, Righi RR, de Oliveira KS. Personal health records: a systematic literature review. J Med Internet Res 2017 Jan 06;19(1):e13 [FREE Full text] [doi: 10.2196/jmir.5876] [Medline: 28062391]

19. Lee H, Kung H, Udayasankaran JG, Kijsanayotin B, B Marcelo A, Chao LR, et al. An Architecture and Management Platform for Blockchain-Based Personal Health Record Exchange: Development and Usability Study. J Med Internet Res 2020 Jun 09;22(6):e16748 [FREE Full text] [doi: 10.2196/16748] [Medline: $\underline{32515743}$ ]

20. Azaria A, Ekblaw A, Vieira T, Lippman A. MedRec: Using Blockchain for Medical Data Access and Permission Management. MedRec: Using Blockchain for Medical Data Access and Permission Management. Innd International Conference on Open and Big Data (OBD); 2016 Presented at: International Conference on Open and Big Data; 22-24 Aug 2016; Vienna p. 2016-2012. [doi: 10.1109/obd.2016.11]

21. A M, C C, R R. Electronic health records in a Blockchain: A systematic review. Electronic health records in a Blockchain: A systematic review 2020:1-16 [FREE Full text] [doi: 10.1177/1460458219866350]

22. Shuaib, Saleous, Shuaib, Zaki. Blockchains for Secure Digitized Medicine. JPM 2019 Jul 13;9(3):35. [doi: 10.3390/jpm9030035]

23. Vazirani AA, O'Donoghue O, Brindley D, Meinert E. Implementing Blockchains for Efficient Health Care: Systematic Review. J Med Internet Res 2019 Feb 12;21(2):e12439 [FREE Full text] [doi: 10.2196/12439] [Medline: 30747714]

24. Angeles R. Blockchain-Based Healthcare: Three Successful Proof-of-Concept Pilots Worth Considering. Blockchain-Based Healthcare: Three Successful Proof-of-Concept Pilots Worth Considering 2018;27(3):38.

25. Rijmenam DV. How Blockchain Will Give Consumers Ownership of their Data. Medium. URL: https://medium.com/ @ markvanrijmenam/how-blockchain-will-give-consumers-ownership-of-their-data-3e90020107e6 [accessed 2020-07-05]

26. Dickson B. How blockchain solves the complicated data-ownership problem. The Next Web. URL: https://thenextweb. com/contributors/2017/08/17/blockchain-solves-complicated-data-ownership-problem/ [accessed 2020-07-05]

27. Ethereum W. Ethereum Whitepaper. Ethereum. URL: https://ethereum.org [accessed 2020-07-07]

28. Zheng Z, Xie S, Dai H, Chen X, Wang H. An Overview of Blockchain Technology: Architecture, Consensus, and Future Trends. In: IEEE International Congress on Big Data (BigData Congress). An Overview of Blockchain Technology: Architecture, Consensus, and Future Trends. InIEEE International Congress on Big Data (BigData Congress); 2017 Presented at: IEEE International Congress on Big Data (BigData Congress); 25-30 Jun 2017; Honolulu p. A. [doi: 10.1109/bigdatacongress.2017.85]

29. Hyperledger. Hyperledger Whitepaper. Hyperledger project. URL: https://www.hyperledger.org/ [accessed 2020-07-07]

30. Quorum Whitepaper. Quorum project. URL: https://www.goquorum.com/ [accessed 2020-07-07]

31. Corda |OSBPFB. Corda Whitepaper. Corda project. URL: https://www.corda.net/ [accessed 2020-07-07]

32. Banks MA. Sizing up big data. Nat Med 2020 Jan 13;26(1):5-6. [doi: 10.1038/s41591-019-0703-0]

33. Moher D, Liberati A, Tetzlaff J, Altman DG, PRISMA Group. Preferred reporting items for systematic reviews and meta-analyses: the PRISMA statement. J Clin Epidemiol 2009 Oct;62(10):1006-1012. [doi: 10.1016/i.jclinepi.2009.06.005] [Medline: 19631508]

34. Hölbl M, Kompara M, Kamišalić A, Nemec Zlatolas L. A Systematic Review of the Use of Blockchain in Healthcare. Symmetry 2018 Oct 10;10(10):470. [doi: 10.3390/sym10100470]

35. Kuo T, Zavaleta Rojas H, Ohno-Machado L. Comparison of blockchain platforms: a systematic review and healthcare examples. J Am Med Inform Assoc 2019 May 01;26(5):462-478. [doi: 10.1093/jamia/ocy185] [Medline: 30907419]

36. Keutzer K, Newton A, Rabaey J, Sangiovanni-Vincentelli A. System-level design: orthogonalization of concerns and platform-based design. IEEE Trans. Comput.-Aided Des. Integr. Circuits Syst 2020;19(12):1523-1543. [doi: 10.1109/43.898830]

37. Burniske C. How blockchain technology can enhance EHR operability. 3iQ. 2016. URL: https://3iq.ca/ how-blockchain-technology-can-enhance-electronic-health-record-ehr-operability/ [accessed 2021-04-01]

38. McFarlane C, Beer M, Brown J, Prendergast N. Patientory: A Healthcare Peer-to-Peer EMR Storage Network v1.0. Patientory. URL: [accessed 2021-04-01]

39. Roehrs A, da Costa CA, da Rosa Righi R. OmniPHR: a distributed architecture model to integrate personal health records. J Biomed Inform 2017 Jul;71:70-81 [FREE Full text] [doi: 10.1016/j.jbi.2017.05.012] [Medline: 28545835] 
40. Badr S, Gomaa I, Abd-Elrahman E. Multi-tier Blockchain Framework for IoT-EHRs Systems. Procedia Computer Science 2018;141:159-166. [doi: 10.1016/j.procs.2018.10.162]

41. Boiani F. Blockchain Based Electronic Health Record Management For Mass Crisis Scenarios?: A Feasibility Study. undefined. Published 2018. Accessed July 14, 2020.

/paper/Blockchain-Based-Electronic-Health-Record-For-Mass-Boiani/1218ed976d8fb5ad33096933defc3ce87cc0 2018:6488.

42. Chen Y, Ding S, Xu Z, Zheng H, Yang S. Blockchain-Based Medical Records Secure Storage and Medical Service Framework. J Med Syst 2018 Nov 22;43(1):1. [doi: 10.1007/s10916-018-1121-4]

43. Dagher GG, Mohler J, Milojkovic M, Marella PB. Ancile: Privacy-preserving framework for access control and interoperability of electronic health records using blockchain technology. Sustainable Cities and Society 2018 May;39:283-297. [doi: 10.1016/j.scs.2018.02.014]

44. Dubovitskaya A, Xu Z, Ryu S, Schumacher M, Wang F. Secure and Trustable Electronic Medical Records Sharing using Blockchain. 2018 Presented at: AMIA Annu Symp Proc. 2018; 2018; San Francisco p. 650-659.

45. Gebremedhin T. Blockchain as a Technology to Facilitate Privacy and Better Health Record Management. Published online September 1. 2018. URL: https://bora.uib.no/handle/1956/19621 [accessed 2020-07-14]

46. MedRec: Patient Control of Medical Record Distribution - IEEE Blockchain Initiative. IEEE Blockchain Initiative. URL: https://blockchain.ieee.org/technicalbriefs/july-2018/medrec-patient-control-of-medical-record-distribution [accessed 2020-07-14]

47. Medicalchain W. Medicalchain Whitepaper. Medicalchain. URL: https://medicalchain.com/en/whitepaper/ [accessed 2020-07-14]

48. Rouhani S, Butterworth L, Simmons A, Humphery D, Deters R. MediChainTM: A Secure Decentralized Medical Data Asset Management System. 2018 Presented at: IEEE Int Conf Internet Things; 2018; Halifax p. A. [doi: 10.1109/cybermatics_2018.2018.00258]

49. Thwin T, Vasupongayya S. Blockchain Based Secret-Data Sharing Model for Personal Health Record System. Inth International Conference on Advanced Informatics: Concept Theory and Applications (ICAICTA); 2018 Presented at: 5th International Conference on Advanced Informatics: Concept Theory and Applications (ICAICTA); 2018; Thailand p. 2018-2015. [doi: 10.1109/icaicta.2018.8541296]

50. Vora J, Nayyar A, Tanwar S. BHEEM: A Blockchain-Based Framework for Securing Electronic Health Records. In: IEEE.: IEEE; 2018 Presented at: 2018 IEEE Globecom Workshops; 2018; Abu Dhabi p. A. [doi: 10.1109/glocomw.2018.8644088]

51. Zhang X, Poslad S. Blockchain Support for Flexible Queries with Granular Access Control to Electronic Medical Records (EMR). 2018 Presented at: IEEE International Conference on Communications (ICC); 2018; Kansas City p. 2018. [doi: 10.1109/icc.2018.8422883]

52. Abouzahra M. Using Blockchain Technology to Enhance the Use of Personal Health Records. In: AMCIS Proc. 2019 Presented at: AMCIS; 2019; Cancun p. 1 URL: https://aisel.aisnet.org/amcis2019/healthcare it/healthcare it/6

53. Alkhushayni S, Al-Zaleq D, Kengne N. Blockchain Technology applied to Electronic Health Records. EasyChair 2019:34-42. [doi: $10.29007 / 2 \times 3 r]$

54. Ray CD. Patient Privacy Ownership of Electronic Health Records on a Blockchain. In: Lecture Notes in Computer Science. New York: Springer; 2019:95-111.

55. Ciampi M. A blockchain architecture for the Italian EHR system. In: ThinkMind Digital Library. 2019 Presented at: The Fourth International Conference on Informatics and Assistive Technologies for Health-Care, Medical Support and Wellbeing (HEALTHINFO 2019); 2019; Valencia URL: https://www.researchgate.net/publication/

337946548 A blockchain architecture for the Italian EHR system

56. Daraghmi E, Daraghmi Y, Yuan S. MedChain: A Design of Blockchain-Based System for Medical Records Access and Permissions Management. IEEE Access 2019;7:164595-164613. [doi: 10.1109/access.2019.2952942]

57. Donawa A, Orukari I, Baker C. Scaling Blockchains to Support Electronic Health Records for Hospital Systems. In: IEEE. 2019 Presented at: IEEE 10th Annual Ubiquitous Computing, Electronics Mobile Communication Conference (UEMCON); 2019; New York p. 2019. [doi: 10.1109/uemcon47517.2019.8993101]

58. Hang, Choi, Kim. A Novel EMR Integrity Management Based on a Medical Blockchain Platform in Hospital. Electronics 2019 Apr 25;8(4):467. [doi: 10.3390/electronics8040467]

59. Harika M, Rahmadika S, Ramdania DR. Blockchain technology for managing an architectural model of decentralized medical record. In: J. Phys.: Conf. Ser. 2019 Dec 14 Presented at: J Phys Conf Ser; 2019; Medan p. 077027. [doi: 10.1088/1742-6596/1402/7/077027]

60. Huang J, Qi Y, Asghar M, Meads A. MedBloc: A Blockchain-Based Secure EHR System for Sharing and Accessing Medical Data. In: Tu Y-C. MedBloc: A Blockchain-Based Secure EHR System for Sharing and Accessing Medical Data. Inth IEEE International Conference On Trust, Security And Privacy In Computing And Communications/13th IEEE International Conference On Big Data Science And Engineering (TrustCom/BigDataSE); 2019 Presented at: 18th IEEE International Conference On Trust, Security And Privacy In Computing And Communications; 2019; New Zealand. [doi: 10.1109/trustcom/bigdatase.2019.00085]

61. Hylock RH, Zeng X. A Blockchain Framework for Patient-Centered Health Records and Exchange (HealthChain): Evaluation and Proof-of-Concept Study. J Med Internet Res 2019 Aug 31;21(8):e13592. [doi: 10.2196/13592] 
62. Jiang S, Wu H, Wang L. Patients-Controlled Secure and Privacy-Preserving EHRs Sharing Scheme Based on Consortium Blockchain. In: IEEE. 2019 Presented at: IEEE Global Communications Conference (GLOBECOM); 2019; Hawaii. [doi: $10.1109 /$ globecom38437.2019.9013220]

63. Koushik A, Jain B, Menon N, Lohia D, Chaudhari SB. Performance Analysis of BlockChain-based Medical Records Management System. 2019 Presented at: 4th International Conference on Recent Trends on Electronics, Information, Communication Technology (RTEICT); 2019; Bengaluru p. 2019-2014. [doi: 10.1109/rteict46194.2019.9016812]

64. Lee SY. PHR System using Blockchain Technology. International Journal of Advanced Trends in Computer Science and Engineering 2019:1-6 [FREE Full text] [doi: 10.30534/ijatcse/2019/84862019]

65. Medibloc. Medibloc Technical Whitepaper. MediBloc. 2019. URL: https://github.com/medibloc/whitepaper [accessed 2020-07-15]

66. MediLOT | Transforming Healthcare For All. MediLOT. URL: https://medilot.com/ [accessed 2020-07-15]

67. Nchinda N, Cameron A, Retzepi K, Lippman A. MedRec: A Network for Personal Information Distribution. MedRec: A Network for Personal Information Distribution. InInternational Conference on Computing, Networking and Communications (ICNC); 2019 Presented at: International Conference on Computing, Networking and Communications (ICNC); 2019; Hawaii p. A. [doi: 10.1109/iccnc.2019.8685631]

68. Nguyen DC, Pathirana PN, Ding M, Seneviratne A. Blockchain for Secure EHRs Sharing of Mobile Cloud Based E-Health Systems. IEEE Access 2019;7:66792-66806. [doi: 10.1109/access.2019.2917555]

69. Rajput AR, Li Q, Taleby Ahvanooey M, Masood I. EACMS: Emergency Access Control Management System for Personal Health Record Based on Blockchain. IEEE Access 2019;7:84304-84317. [doi: 10.1109/access.2019.2917976]

70. Reen G, Mohandas M, Venkatesan S. Decentralized Patient Centric e- Health Record Management System using Blockchain and IPFS. In: IEEE. 2019 Presented at: InIEEE Conference on Information and Communication Technology; 2019; Pakistan p. 2019. [doi: $10.1109 /$ cict48419.2019.9066212]

71. Sangeetha R. Electronic Health Record System using Blockchain. Int Res J Multidiscip Technovation 2019 Mar 25;1(2):57-61. [doi: 10.34256/irjmt1927]

72. Shahnaz A, Qamar U, Khalid A. Using Blockchain for Electronic Health Records. IEEE Access 2019;7:147782-147795. [doi: 10.1109/access.2019.2946373]

73. Shekhawat G. Cloud-chain: Revamp Health Record System Using Blockchain. Website. 2019. URL: [accessed 2020-07-14]

74. Thwin T, Vasupongayya S. Blockchain-Based Access Control Model to Preserve Privacy for Personal Health Record Systems. Security and Communication Networks 2019:1-16 [FREE Full text] [doi: 10.1155/2019/8315614]

75. Tian X. Blockchain-based secure medical record sharing system. Website. 2019. URL: http://eprints.utar.edu.my/3435/ [accessed 2020-07-15]

76. Toshniwal B, Podili P, Reddy R, Kataoka K. PACEX: PAtient-Centric EMR eXchange in Healthcare Systems using Blockchain. In: IEEE. PACEX: PAtient-Centric EMR eXchange in Healthcare Systems using Blockchain. InIEEE 10th Annual Information Technology, Electronics and Mobile Communication Conference (IEMCON); 2019 Presented at: IEEE 10th Annual Information Technology, Electronics and Mobile Communication Conference (IEMCON); 2019; Vancouver p. 2019. [doi: 10.1109/iemcon.2019.8936258]

77. Wang S, Zhang D, Zhang Y. Blockchain-Based Personal Health Records Sharing Scheme With Data Integrity Verifiable. IEEE Access 2019;7:102887-102901. [doi: 10.1109/access.2019.2931531]

78. Wang Y, Zhang A, Zhang P, Wang H. Cloud-Assisted EHR Sharing With Security and Privacy Preservation via Consortium Blockchain. IEEE Access 2019;7:136704-136719. [doi: 10.1109/access.2019.2943153]

79. Sihua W, Jang D. Electronic medical record security sharing model based on blockchain. In: Proceedings of the 3rd International Conference on Cryptography, Security and Privacy. 2019 Presented at: ICCSP '19; 2019; Japan. [doi: 10.1145/3309074.3309079]

80. Goni N, Ahmed S, Ibrahim A. A P2P Optimistic Fair-Exchange (OFE) Scheme for Personal Health Records Using Blockchain Technology. In: Springer.: Springer; 2020 Presented at: 3rd International Conference on Wireless, Intelligent and Distributed Environment for Communication; 2020; Toronto p. 1-21. [doi: 10.1007/978-3-030-44372-6_1]

81. Arunkumar B, Kousalya G. Blockchain-Based DecentralizedSecure Lightweight E-Health System for Electronic Health Records. In: Intelligent Systems, Technologies and Applications. New York: Springer; 2020:273-289.

82. Aswin A, Basil K, Viswan V, Reji B, Kuriakose B. Design of AYUSH: A Blockchain-Based Health Record Management System. In: Inventive Communication and Computational Technologies. Singapore: Springer Singapore; 2020.

83. Cao Y, Sun Y, Min J. Hybrid blockchain-based privacy-preserving electronic medical records sharing scheme across medical information control system. Measurement and Control 2020:1-14 [FREE Full text] [doi: 10.1177/0020294020926636]

84. Charanya RR. SeFra: A Secure Framework to Manage eHealth Records Using Blockchain Technology. International Journal of E-Health and Medical Communications (IJEHMC) 2020:1-5. [doi: 10.4018/ijehmc.2020010101]

85. Kavathekar S, Patil R. Data Sharing and Privacy Preserving of Medical Records Using Blockchain. In: Lecture Notes on Data Engineering and Communications Technologies. New York: Springer; 2020:65-72.

86. Kim M, Yu S, Lee J, Park Y, Park Y. Design of Secure Protocol for Cloud-Assisted Electronic Health Record System Using Blockchain. Sensors 2020 May 21;20(10):2913. [doi: 10.3390/s20102913] 
87. Kung H, Cheng Y, Lee H, Hsu C. Personal Health Record in FHIR Format Based on Blockchain Architecture. In: Lecture Notes in Electrical Engineering. New York: Springer; 2020:1776-1788.

88. Sharma S, Mishra A, lala A, Singhai D. Secure Cloud Storage Architecture for Digital Medical Record in Cloud Environment Using Blockchain. SSRN Journal 2020:1-5. [doi: 10.2139/ssrn.3565922]

89. Sharma Y, Balamurugan B. Preserving the privacy of electronic health records using blockchain. Procedia Comput Sci 2020;173(1):171-180. [doi: 10.1016/j.procs.2020.06.021]

90. Tith D, Lee JS, Suzuki H, Wijesundara WM, Taira N, Obi T, et al. Application of blockchain to maintaining patient records in electronic health record for enhanced privacy, scalability, and availability. Healthc Inform Res 2020 Jan;26(1):3-12 [FREE Full text] [doi: 10.4258/hir.2020.26.1.3] [Medline: 32082695]

91. Verdonck M, Poels G. Architecture and Value Analysis of a Blockchain-Based Electronic Health Record Permission Management System. In: Proceedings of 14th International Workshop on Value Modelling and Business Ontologies.: Ghent University; 2020 Presented at: 14th International Workshop on Value Modelling and Business Ontologies; Jan 16, 2020; Brussels, Belgium URL: https://biblio.ugent.be/publication/8654183

92. Wu X, Han Y, Zhang M, Zhu S. Secure personal health records sharing based on blockchain and IPFS. In: Trusted Computing and Information Security. Communications in Computer and Information Science. New York: Springer; 2020.

93. Layer. Ethereum. 2020. URL: https://ethereum.org

94. Neo Smart Economy. NEO team. URL: https://neo.org/ [accessed 2020-07-15]

95. NeoFS data storage, payment, and auditing demoed at Consensus 2019. Neo News Today. 2020. URL: https://neonewstoday. com/development/neofs-data-storage-payment-and-auditing-demoed-at-consensus-2019/ [accessed 2020-07-15]

96. China Bans Digital Coin Offers as Celebrities Like Paris Hilton Tout Them. Walls Street Journal. URL: https://www. wsj.com/articles/some-digital-coins-are-up-2-800-what-could-go-wrong-1504522801 [accessed 2020-12-24]

97. Kim C. South Korea bans raising money through initial coin offerings. Reuters. URL: https://www.reuters.com/article/ us-southkorea-bitcoin-idUSKCN1C408N.Published September 29, 2017 [accessed 2020-12-24]

98. SEC Issues Investigative Report Concluding DAO Tokens, a Digital Asset, Were Securities. SEC.hov. 2020. URL: https:/ /www.sec.gov/news/press-release/2017-131 [accessed 2021-04-01]

\author{
Abbreviations \\ BFT: Byzanthine fault tolerance \\ CS: computer science \\ EHR: electronic health record \\ EMR: electronic medical record \\ FHIR: Fast Healthcare Interoperability Resource \\ GDPR: General Data Protection Regulation \\ HF: Hyperledger Fabric \\ HIPAA: Health Insurance Portability and Accountability Act \\ HL-7: health level 7 \\ ICO: initial coin offering \\ IPFS: Interplanetary File System \\ NeoFS: NEO file storage system \\ PHR: personal health record \\ PRISMA: Preferred Reporting Items for Systematic Reviews and Meta-analyses \\ PoW: proof of work \\ UI: user interface
}

Edited by $R$ Kukafka; submitted 17.10.20; peer-reviewed by CA da Costa, TT Kuo, JH Lee; comments to author $21.12 .20 ;$ revised
version received 25.12.20; accepted 16.03.21; published 13.04.21
Please cite as:
Fang HSA, Tan TH, Tan YFC, Tan CJM
Blockchain Personal Health Records: Systematic Review
J Med Internet Res $2021 ; 23(4):$ e25094
URL: $\underline{\text { https://www.jmir.org/2021/4/e25094 }}$
doi: $10.2196 / 25094$
PMID:


CHao Sen Andrew Fang, Teng Hwee Tan, Yan Fang Cheryl Tan, Chun Jin Marcus Tan. Originally published in the Journal of Medical Internet Research (http://www.jmir.org), 13.04.2021. This is an open-access article distributed under the terms of the Creative Commons Attribution License (https://creativecommons.org/licenses/by/4.0/), which permits unrestricted use, distribution, and reproduction in any medium, provided the original work, first published in the Journal of Medical Internet Research, is properly cited. The complete bibliographic information, a link to the original publication on http://www.jmir.org/, as well as this copyright and license information must be included. 